\title{
Managing the Uninsured With a Community Network
}

\author{
Paul B. Roth, MD \\ Dean, School of Medicine, Vice President \\ for Health Sciences, University of New \\ Mexico, Albuquerque, NM
}

Conflicts of interest: none reported

\section{CORRESPONDING AUTHOR}

Paul B. Roth, MD

Executive Vice President for

Health Sciences

MSC09 5300

University of New Mexico

Albuquerque, NM 87131-5001

proth@salud.unm.edu
Ann Fam Med 2006;4(Suppl 1):S28-S31. DOI: 10.1370/afm.560.

\section{INTRODUCTION}

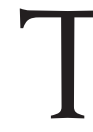

oday, more than 45 million Americans are uninsured and another 30 million are underinsured. ${ }^{1}$ Medical schools and teaching hospitals

form a critical component of our nation's medical safety net, yet this role comes at enormous cost. Although our teaching hospitals comprise only $6 \%$ of all hospitals nationally, they provide more than one half of all charity care. The Association of American Medical Colleges (AAMC) reports that the cost of this care in 2003 was $\$ 5.9$ billion. ${ }^{2}$ The problem is exacerbated in states such as New Mexico, where the level of employerbased insurance is low and the level of illegal immigration is high.

Hospitals nationally are facing growing public scrutiny of how they bill the uninsured. Congress has been expressing increased concern. Advocates for the poor have framed the problem of such billing practices as a public health and consumer protection issue. In 2003, the American Hospital Association (AHA) sent an alert to 4,800 hospitals across the country urging its members to stop using harsh bill collection tactics that reflect poorly on the industry.

Hospitals feared they would be violating government Medicare regulations, preventing them from billing anyone less than they bill the federal government. They also interpreted the federal regulations as requiring them to aggressively try to collect from all patients, insured or not. This policy was clearly related to the fact that medical bills are now the second leading cause of bankruptcy in the United States, as reported in Health Affairs. ${ }^{3}$ The Secretary of Health and Human Services had to intervene. The Wall Street Journal reported that Tommy Thompson told the AHA that it had mischaracterized government policy and was wrong in stating that government rules prohibited them from billing uninsured patients all but full price. ${ }^{4} \mathrm{Nei}-$ ther were they obligated to aggressively collect bills from the uninsured.

Today, academic health centers (AHCs) are seeking innovative solutions to the financial and health service challenges presented by growing numbers of uninsured seeking care at their institutions. Our professional organizations are offering approaches. The AAMC proposes Protecting America's Uninsured, a resource that recommends policy alternatives and cites approaches from different AHCs that are working to improve access and, in some cases, reduce costs. ${ }^{2}$ The Association of Academic Health Centers initiated Academics for Access to Health Care, a multiyear national education campaign aimed at policy makers and the public about the need to address health care for the uninsured.

\section{LOCAL SETTING AND CONTEXT}

The University of New Mexico Health Sciences Center is a small to moderate-sized, public AHC that operates on an $\$ 800$ million annual budget, 
about $65 \%$ of it allocated to its public University Hospital, about 30\% to its school of medicine. Although the state of New Mexico has been a committed sponsor of the center, the state's poverty level and the rising cost of health care have contributed to a decline in the state subsidy proportion to less than $20 \%$ of the center's operating budget. Our hospital has been the recipient of a steadily increasing subsidy from county property taxes, receiving $\$ 54$ million annually through the imposition of a mill levy property tax. Yet the bottom line of both the school of medicine and its public teaching hospital are in jeopardy because of falling reimbursement from public and private third-party payers and the rising number of uninsured who seek our care. The uninsured now comprise about $35 \%$ of our AHC's patients in a state that has one of the highest rates in the nation of medically uninsured, at about $25 \%$.

Until recently, our strategy for protecting our center from the growing burden of uncompensated care is one familiar to all AHCs in the United States. Under the threat of "no margin, no mission," solutions to our falling income led to a series of income-generating strategies that also had unintended, negative consequences for the uninsured. We invested heavily in high-end tertiary and quaternary care. Although we sought contracts to attract a paying customer base, we allowed the emergence of high, upfront payment policies for the uninsured, neglecting the social consequences of these policies on access to care for these most vulnerable patients.

We saw an inexorable shift of state-funded faculty effort from education of our medical students to hospital service, pitting our education mission against our service mission. All hospital subsidies of community outreach activities were eliminated. Polarization grew between those at our AHC whose focus was on financial viability and those whose focus was on our institutional commitment as the ultimate safety net provider to all who arrived at our doors needing care.

The reputation we had built as an innovative, community-responsive institution was being undermined by the corrosive tensions and polarization that had emerged. There was a growing community perception that the University Hospital cared more about its bottom line than about the health of the urban and rural communities it served.

Tensions rose to such a level that community advocacy groups brought suit against the hospital, and an informal coalition of grassroots advocacy groups, county commissioners, and even representatives of the Democratic Party complained to the governor. The governor called for a broadly representative summit meeting of all community stakeholders to explore how the hospital cared for the poor and what actions should be taken to address the many perceived problems.

\section{A NEW DIRECTION}

Clearly, I thought our institutional mission was being threatened and we needed to embark quickly on a new direction. I felt strongly that we needed to understand our community, to regain their trust as a partner on their behalf, and to ensure their health while protecting the survivability of our AHC. I needed wise counsel and internal allies to develop a strategic plan of attack.

Among all our academic departments, the Department of Family and Community Medicine had the most widespread and consistent track record of community engagement, partnership, and accomplishment. Its programs had almost single-handedly brought us national and international recognition as an educational powerhouse in rural health and community-based learning Its resident graduates stayed in state and distributed themselves in rural counties far more than graduates of any other residency - enhanced even more so thanks to the 3 rural-based programs. This presence was of strategic importance to us when these resident graduates and their community representatives came out to support AHC programs at the state legislature, which is dominated by rural lawmakers.

In addition, our Department of Family and Community Medicine has taken seriously its responsibility to recruit and train an ethnically diverse workforce. Its faculty has the highest percentage of Hispanic and Native Americans among all departments, at $25 \%$. My office therefore increasingly has relied on this department to lead the way in developing policies and programs relevant to priority community needs. I have dipped into their ranks of young faculty to develop and lead important programs and deanships, such as the Assistant Dean for Research, the Associate Dean for Student Affairs, the new position of Associate Dean for Diversity, and the director of a new Center for Native American Health. Each has made important links with community groups unsurpassed in the recent past.

With the help and recommendations of my colleagues in the Department of Family and Community Medicine, I began to meet with different community stakeholders and advocacy groups and took the following actions:

1. An appointed committee defined and clarified that our University Hospital in addition to being an academic teaching hospital has a strong and historical public mission and that our AHC should relate to our community as a true partner.

2. The widely criticized Self-Pay Policy for uninsured patients was abolished. Now, all uninsured, low-income patients are charged the same affordable, sliding-scale, upfront copays for visits, drugs, tests, and hospitalizations. 
3. I announced plans to create an Office of Community Affairs with a director trusted by the community. A community advisory board will help advise this office, as well as the Office of the Vice President for Health Sciences, to ensure that AHC programs and plans are consistent with our public mission and take into account the community's priorities.

We know that the uninsured experience a greater burden of illness than the insured, and that economic and social factors play a substantial role in the determinants of their illnesses. In addition, we know that a relatively small number of high users of our health care system, the top $5 \%$, consume about $50 \%$ of our resources. And it is estimated that $70 \%$ of the underlying causes of medical problems presenting to our emergency departments by these top 5\% are behavioral, and $70 \%$ of those are related to alcohol and substance abuse. I am both a family physician and an emergency physician, and I continue to work in our emergency department. I realize that the high-quality medical services we provide there are insufficient to address those underlying social causes of disease; thus, I have invested in creating an intense case management system for uninsured high users of our system. Called Care One and in its infancy, it will link with the network of safety net social and behavioral health services in the community established by our Department of Family and Community Medicine so that our neediest patients benefit from a seamless system of on- and offcampus care. Again, the full value of our AHC's efforts in the care of the uninsured can only be realized by partnering with community stakeholders.

Another innovative way we have found to add more resources for this population is our State Care Initiative. We have been able to expand the eligibility to Medicaid through a waiver granted by the federal government and move individuals off indigent status. This means that for every person enrolled in this fashion, the institution will receive nearly $\$ 1,000$ per year. Again, the Department of Family and Community Medicine was at the forefront in helping us design this program with its community partners.

Concerning our educational mission, we want our graduates to address more effectively the health of their communities. We are therefore modifying our medical school curriculum so that every student will eventually graduate with a Certificate of Public Health. The Department of Family and Community Medicine has been the lead department in promoting and piloting this curriculum with our students, residents, and faculty.

Finally, I have taken steps to mobilize our innovative education programs to strengthen our ties and service to New Mexico's rural counties and under- represented minority groups by building on the community-based innovations and practice outcomes of our Department of Family and Community Medicine. With support from our university and our state legislature, especially its rural representatives, we have decided to expand our entering medical school class from 75 to 100 students, but in an entirely new fashion. These students will enter a combined BA-MD program and will be recruited preferentially from rural and ethnic minority communities in the state. Because rates of poverty and lack of medical insurance are critically high in these communities, and because we are orienting the program to graduating physicians who will return to rural and underserved communities in the state, we hope that this long-term education strategy will address health care access for the uninsured.

\section{STRATEGIES IN FORMING PARTNERSHIPS}

The following 3 strategies used in New Mexico foster successful academic-community partnerships for the uninsured and seem applicable to any setting.

1. Build trust between the AHC and marginalized groups and their advocates.

- Invite community representatives to participate in an effective, highly visible advisory capacity to the AHC leadership, rather than as token parties in marginal roles.

- Demonstrate responsiveness and willingness to change when community groups offer advice on their priorities.

- Identify leadership talent within the family medicine faculty able to bridge the interests and needs of the community and the AHC.

2. Ally with other safety net providers in the community, especially community health centers (CHCs). These centers are the natural allies of AHCs in addressing the needs of the uninsured. But $\mathrm{CHCs}$ are often suspicious of AHC motives, fearing a "takeover" or that the AHC is only interested in off-loading their uninsured patients. And whereas AHCs have 3 missions, $\mathrm{CHC}$ s have only 1 , service, and they are uncomfortable with the amount of time that may be diverted to teaching and away from "productivity." The AHC can build trust using the model developed by the Department of Family and Community Medicine, which accomplished the following:

- CHCs were established as teaching sites for medical students and residents, with $\mathrm{CHC}$ physicians appointed to the volunteer faculty, thereby making these centers more attractive for potential recruits.

- Joint recruiting strategies were fostered, and CHCs were promoted to senior residents as preferred positions of employment. This action reduced sharply 
the cost of $\mathrm{CHC}$ recruitment and, in 1 case, led to the appointment of a CHC medical director who is concurrently a faculty member in the Department of Family and Community Medicine.

- Family medicine's inpatient service became the accepting service for $\mathrm{CHC}$ patients that host teaching programs, thereby permitting direct admissions and fostering timely communication between the referring $(\mathrm{CHC})$ physician and the receiving (AHC-family medicine) physician.

- The AHC contracted with the CHCs to provide primary care services to the uninsured, thereby expanding the AHC's capacity in primary care and increasing its ability to schedule paying patients while benefiting the $\mathrm{CHC}$ with another funding stream for indigent care.

- Family medicine and our CHCs have successfully applied for state funding and for private foundation and federal grant funding for innovations in service and education, building collaborative relationships and considerable trust along the way.

3. Build on the unique role family medicine plays with community groups. As a dean, I must balance competing demands of departments. Some view family medicine narrowly_as a primary care system that feeds into the AHC specialties; however, I have found a larger and more important role for the Department of Family and Community Medicine that helps other departments and the institution as a whole. Members of this department assume a leadership role in offering guidance to policy makers within the AHC and in county and state government when they plan programs addressing health needs across the state. Because they are community oriented, with a strong base of community relationships, they can help build important bridges between the AHC and the communities and the legislature. For example, beyond their known education and service outreach activities, department members have built an important practice-based research network, RIOS Net (Research Involving Outpatient Settings Network), which links more than 250 primary care physicians, mainly in practices within CHCs and the Indian Health Service that care for the indigent and uninsured. This network has helped the AHC compete successfully for National Cancer Institute and National Institutes of Health Roadmap funding.

Today, former critics of the AHC on the county commission, in state government, and among community advocacy groups have become allies and informal advisors to my office. Community advocates, formerly skeptical of our AHC's efforts, are now willing to join the $\mathrm{AHC}$ in pressing state government for more resources to better care for the uninsured and to strengthen programs on their behalf.

The road ahead is uncertain, but we are in a stronger position because the Department of Family and Community Medicine has helped our AHC become a more trusted partner of our community, and we are seeing different community stakeholders now join the $\mathrm{AHC}$ in strengthening its programs and seeking state and other funding for its priority programs.

To read or post commentaries in response to this article, see it online at http://www.annfammed.org/cgi/content/full/4/suppl_1/s28.

Submitted December 15, 2005; accepted February 27, 2006.

Key words: Academic health centers; hospitals, teaching; community health centers; uninsured; low-income population; advisory committees; family medicine; community health networks; rural population; medically underserved area; minority groups

\section{References}

1. DeNavas-Walt $C$, Proctor $\mathrm{B}$, Lee $\mathrm{CH}$, for the US Census Bureau. Income, Poverty, and Health Insurance Coverage in the United States: 2004. Washington, DC: US Government Printing Office; 2005:60-229.

2. Association of American Medical Colleges. Protecting America's Uninsured. Available at: http://www.aamc.org/uninsured/start.htm. Accessed 17 April 2006.

3. Himmelstein DU, Warren E, Thorne D, Woodhandler S. MarketWatch: illness and injury as contributors to bankruptcy. Health Aff (Millwood). February 2, 2005. Available at: http://content.healthaffairs.org/cgi/ content/abstract/hlthaff.w5.63. Accessed 17 April 2006.

4. Lagnado L. HHS chief scolds hospitals for their treatment of uninsured. Wall Street Journal. February 20, 2004;A:1. 